\title{
Staying Cool Across the First Year of Middle School
}

\author{
Amy Bellmore • Vanessa M. Villarreal • \\ Alice Y. Ho
}

Received: 21 June 2010/Accepted: 28 August 2010/Published online: 15 September 2010

(C) The Author(s) 2010. This article is published with open access at Springerlink.com

\begin{abstract}
As students transition into middle school they must successfully negotiate a new, larger peer context to attain or maintain high social standing. The goal of this study was to examine the extent to which the maintenance, attainment, and loss of a cool status over the course of the sixth grade is associated with student and classroom levels of physical, verbal, and relational aggression. To address this goal, we studied a sample of 1985 (55\% girls) ethnically diverse adolescents from 99 sixth grade classrooms in the United States. Attaining a cool status at any point across the school year was associated with stronger aggressive reputations. Additionally, classroom norms for aggressive behavior moderated the association between changes in aggression over the school year and the stability of coolness such that students who maintained their coolness across the school year showed greater increases in their verbally aggressive reputations from fall to spring when they were in classrooms with higher levels of aggression. The findings illustrate the importance of fitting in with social norms for maintaining a high social status among a new set of peers in middle school.
\end{abstract}

A. Bellmore $(\varangle)$

Department of Educational Psychology, University

of Wisconsin-Madison, Madison, WI, USA

e-mail: abellmore@wisc.edu

V. M. Villarreal

Department of Education, University of California, Los Angeles, Los Angeles, CA, USA

A. Y. Ho

Academic Advancement Program, University of California, Los Angeles, CA, USA
Keywords Coolness - Popularity · Aggression · Middle school

\section{Introduction}

Attaining and maintaining high social status within the peer group is particularly important during early adolescence as concerns over peer evaluations increase and the peer structure changes to a hierarchically organized peer system (Cairns and Cairns 1991; Corsaro and Eder 1990; Rubin et al. 2006; Schäfer et al. 2005). A growing body of research on peer relationships has differentiated those who are sociometrically popular from those who are perceived popular. Sociometric popularity is an index of peer liking or preference whereas perceived popularity measures social visibility, centrality, power, and also incorporates coolness (Adler et al. 1992; Cillessen and Rose 2005; Parkhurst and Hopmeyer 1998). Relative to other social relationship priorities (e.g., friendships), being popular peaks in importance in early adolescence (LaFontana and Cillessen 2010), a developmental period generally characterized by heightened concern about peer approval and "fitting in" with the local norms (Eccles and Midgley 1989). Being popular in this developmental period is desirable not only because it reflects a positive or powerful position based on the collective opinion of the peer group but also because it may offer specific provisions such as access to certain peers and opportunities to develop social competencies unavailable to individuals with lower peer status (Rubin et al. 2006). Given these advantages, adolescents with high social status will want to maintain their status and adolescents with average or low social status will want to ascend their peer hierarchy. The goal of the present study is to examine how both student and 
classroom characteristics are associated with whether students maintain, attain, or lose their status, defined as coolness, across the first year of middle school.

\section{Characteristics of High Status Adolescents}

Existing work establishing the characteristics of high status youth is derived from diverse theoretical and methodological traditions. These include ethnographic approaches conducted by anthropologists and sociologists interested in understanding microsocieties present within peer settings and quantitative approaches conducted by psychologists interested in identifying normative or atypical behaviors associated with high status. These methods have yielded consistent differences between being well-liked and being popular. For example, participant observation and more traditional quantitative studies both link coolness with perceived popularity (e.g., Adler et al. 1992; Closson 2008; Meisinger et al. 2007), but not with sociometric popularity. With respect to behavioral differences, one of the most robust findings in the emerging literature differentiating sociometric popular from perceived popular youth is their use of aggression. Whereas aggressive behavior may cost likeability (Cillessen and Rose 2005; Coie et al. 1982; Rubin et al. 2006), it seems that aggression can be used skillfully to assist adolescents in attaining perceived popularity (Bowker et al. 2010; Hawley 2003; LaFontana and Cillessen 2002; Parkhurst and Hopmeyer 1998; Rose et al. 2004). For example, researchers have found that perceived popular students strategically use aggression to manipulate the social dynamics of their peer system (Adler and Adler 1995; Merten 1997) and increase their use of aggression as a means to protect their high status (Sandstrom and Cillessen 2006). There is also evidence that adolescents make judgments about what behaviors are rewarded by peers and these judgments influence how they later behave. Juvonen and Ho (2008) found that students who were more likely to associate high social status with the use of aggression when evaluating their peers in sixth grade also demonstrated increases in their own use of aggression during the next school year. Coolness, like perceived popularity, has also been found to be associated with higher levels of aggression (Hoff et al. 2009; Rodkin et al. 2006). Thus, engaging in aggressive behavior during early adolescence may be motivated both by the desire to gain and maintain high status.

Being visible is an important component of being popular (Eder 1985), and certain forms of aggression may achieve this visibility better than others. For example, high levels of overt physical or verbal aggression may serve to promote the attainment of a cool status relative to high levels of relational aggression which may be carried out in more subtle ways. The form of aggression that best promotes the attainment of a cool status may also differ according to gender. It has been argued that physical aggression may be used to demonstrate dominance among a new set of peers in middle school by boys in particular (Pellegrini and Bartini 2000; Pellegrini and Long 2002). Unresolved is whether the maintenance of a cool status, once an initial peer hierarchy has been established, is also associated with boys' use of physical aggression. If so, this would indicate a complementary process whereby cool status and the use of physical aggression to maintain one's cool status across time both reflect (i.e., are markers of) social skillfulness (Cillessen and Bellmore in press). A separate line of research points to perceived popularity as a marker of social skillfulness (Andreou 2006) or social intelligence (Peeters et al. 2010). However, this work indicates that relational aggression is more strongly predictive of perceived popularity than is physical aggression (Andreou 2006). Further, since relational aggression has been found to be most strongly predictive of perceived popularity for girls (Cillessen and Mayeux 2004), the use of relational aggression to promote stability of coolness may be more evident for girls than boys. Given these contrasting predictions about the forms of aggression most strongly predictive of perceived popularity, both the form of aggression and its interaction with gender are important considerations to understanding the maintenance of a cool status in early adolescence.

\section{Maintenance of Social Status}

The maintenance of high social status is not an easy feat. A recent study examining perceived popularity reported that $62 \%$ of popular adolescents maintained their status from the spring of 5th grade to the fall of 6th grade (Bowker et al. 2010). A meta-analysis examining the stabilities of all sociometric categories found that only $35 \%$ of adolescents remained stable in their status groupings (Cillessen et al. 2000). Movement into a higher status category is even more difficult. Bowker and her colleagues reported that only $23 \%$ of students were able to move into the popular status. Others have found even smaller proportions of students who gain status across the school year-Lopes et al. (2002) found that less than $2 \%$ of students who were sociometrically popular in 5th grade were able to move into the popular status in 6th grade. Given that not all students are able to hold on to their high status and that even fewer are able to move into a higher status, it is important to identify whether the characteristics reviewed previously that are associated with continuous measures of social status also promote the attainment and maintenance of coolness status across time.

These factors also likely depend on both characteristics of the adolescent him or herself and dynamics of their peer 
group social context (Cillessen et al. 2000). The persongroup dissimilarity model states that a social group is more likely to negatively evaluate individuals whose behaviors deviate from the group norm (Wright et al. 1986). In classroom settings, aggressive students who deviated from behavioral norms of the whole classroom were more likely to be rejected by their peers (Stormshak et al. 1999; Wright et al. 1986) and aggressive students whose behavior matched the behavioral norms of high status peers in particular were more likely to be accepted by their peers (Dijkstra et al. 2008). Just as a social status is related to the norms in a social setting, it is possible that the stability of social status is as well. That is, one mechanism for losing or never attaining high status might be poor fit with the norms and values in the setting. On the flip side, students whose behaviors are consistent with the setting norms should receive positive reinforcement from the peer group in the form of maintained status.

\section{The Present Study}

This study examined how student and classroom aggression were related to the maintenance and attainment of cool status in early adolescence. We focused on coolness because it has been identified by adolescents as a core attribute of popularity (Adler et al. 1992; Closson 2008). We do not view coolness and perceived popularity to be identical, but we expect that they each represent a similar form of high social status that is distinct from social preference. Further, to best identify the unique association of coolness stability with aggression, we included social preference as a key control variable in our study. Based on peer nominations of "coolness" collected both in fall and spring of 6th grade, we classified students into stability groups. "Stable cool" students were those who were identified as among the coolest of their peers in both fall and spring, those classified as "became cool" were those who were among the coolest in spring but not in fall, "became not cool" students were those who were among the coolest in fall but not spring, and "never cool" were those who were never among the coolest in their class. We adopted a person-oriented analytic approach because it allowed us to examine behavioral differences among subgroups of students, in this case different coolness stability groups. Classifying students into extreme groups is a useful technique for understanding individual differences in development (Magnusson and Cairns 1996) and has been primarily utilized by peer relations researchers interested in linking sociometric status groupings to psychosocial adjustment (Cillessen 2009). In this study, our classifications were based on status groupings at the beginning and end of sixth grade.
Once students were classified into coolness stability groups, we then compared their aggressive reputations. Based on established cross-sectional positive associations between aggression and perceived popularity reviewed earlier, we hypothesized that those who maintained coolness would score highest on aggression in spring compared to those who lost or never attained a cool status. We examined three forms of aggression—physical, verbal, and relational-to investigate whether certain forms were more strongly associated with the stability of a cool status than others. Investigating all three forms also allowed us to make claims about the unique association that each form of aggression had with coolness stability. Based on earlier research linking aggression and status (see Cillessen and Mayeux 2004; Pellegrini and Bartini 2000; Pellegrini and Long 2002), there was also reason to expect that the form of aggression associated with greater stability in coolness may vary by gender such that the stability of coolness is most strongly associated with physical aggression for boys and with relational aggression for girls.

We also examined the influence of classroom norms on how the stability of coolness was related to changes in all three forms of aggression over the course of one school year. We believed that maintenance of status would be associated with good fit between students' behaviors and classroom norms. Therefore, we hypothesized that those who maintained their cool status by the end of the year would display increases in aggression across the school year particularly when they were in classrooms with higher levels of aggressive behavioral norms.

\section{Methods}

\section{Participants}

Participants were 1985 (55\% female) sixth grade students from 99 classrooms across 11 Los Angeles area middle schools located in predominantly low SES neighborhoods. Across the 99 classrooms, the average class size was 21.72 ( $S D=6.26)$. Based on students' self reports of ethnicity at the first time point, the ethnic composition was $45 \%$ Latino, 26\% African American, 11\% Asian, 10\% Caucasian, and $8 \%$ other/multiethnic youth.

\section{Procedure}

The participants were part of the UCLA Peer Relations Project, a 6-wave, 3-year study of the social-cognitive and social-contextual factors associated with peer harassment. Within each school, part of the grade was recruited by sampling one third to half of the classrooms in the school. Students from classrooms whose teachers expressed 
interest in the study took home letters and consent forms that explained the study. Only students who returned a signed consent form granting permission from their guardians were allowed to participate in the study. To increase return rate, a raffle was conducted on the day of data collection for everyone who returned their signed consent form, with or without parental permission to participate. Across the 11 participating schools, $75 \%$ of the 3,511 distributed consent forms were returned. Of those students who returned a signed consent form, $91 \%$ of their parents granted permission for them to participate. Data were collected from each cohort during the fall and spring of students' sixth grade year. The percentages of students of the 2,331 total sample who participated in each wave were as follows: $99 \%$ in fall and $97 \%$ in spring of 6 th grade. Participating students and teachers filled out written questionnaires in their classrooms.

Because all of the participating schools organized their 6th graders into teams or clusters, students spent several periods a day with the same classmates and a small number of teachers. This helped to ensure that students knew one another well enough to complete ratings of their peers' social behavior. As an additional step to maximize familiarity, the fall data collection was carried out several weeks into the semester. The entire questionnaire was administered within the classroom during one class period (approximately $45 \mathrm{~min}$ long). All instructions and questionnaire items were read aloud by a graduate research assistant while students followed along and recorded their own responses. For each student who participated, \$5 was awarded to a classroom fund to be spent to benefit the classroom students at the teachers' discretion.

\section{Measures}

\section{Stability of Coolness Status}

Classroom-based peer nominations were used to assess the stability of coolness status across the school year. Each semester, participants were provided with a roster that contained the names of participating students in their homeroom class. Students utilized this roster to nominate up to four classmates whom they considered to be "the coolest kids." The number of nominations that students received from their peers was summed and standardized within classroom.

To determine the stability of students' cool status, separately for fall and spring, the $10 \%$ of students who received the highest number of nominations from their classmates for coolness were classified as "cool" and the other students were classified as "not cool." Next, the combination of the status that each student was assigned to at each time point was utilized to determine the stability of coolness: those perceived as cool during both semesters ("stable cool," $n=91$ ), those perceived as not cool in fall but who then gained coolness in spring ("became cool," $n=98$ ), those perceived as cool in fall but who lost their cool status in spring ("became not cool," $n=100$ ), and those who were perceived as not cool at both time points ("stable not cool," $n=1,696$ ). We utilized the top $10 \%$ cut-off point because we wanted a stringent criterion for identifying stable social status. Studies examining group differences with peer nominations frequently specify one standard deviation as a meaningful designation (e.g., Coie et al. 1982) but there is great variability in the cut off used (e.g., .5 of a standard deviation was used by Closson (2008) and the 67th percentile was used by Bowker et al. (2010)). Thus, there is no one consistent cut off point that is utilized because where it should be placed and how it should be identified and validated depends on its desired use (see Nylund et al. 2007). In our sample, Z-scores of 1 and above at spring captured the top 14\% of the sample for coolness, values similar to our $10 \%$ cut off.

\section{Social Preference}

Peer nominations were utilized in the same way to assess social preference. Students nominated classmates whom they "like to hang out with" and "do not like to hang out with" and standardized scores were created. Next, the standardized values for the disliking question were subtracted from the standardized values for the liking question, and the resulting scores were standardized within classroom to create a social preference score for each student.

\section{Students' Aggressive Reputations}

Peer nominations were also utilized to determine participants' aggressive reputations in both fall and spring. Physical, verbal, and relational aggression were measured, respectively, by inquiry of three distinct items: "Who fights or pushes other kids around?", "Who puts kids down or makes fun of others?", and "Who spreads nasty rumors about others?" While referring to the roster, participants were asked to nominate up to four classmates who most represented each item's criteria. As before, the number of nominations that students received from their peers for each question was summed and standardized within classroom. In spring, the correlations between the forms of aggression were: 80 between physical and verbal aggression, .70 between physical and relational aggression, and .75 between verbal and relational aggression.

\section{Classroom Aggression Behavioral Norms}

A classroom-level (aggregated) score of aggression was computed based on teacher ratings of the extent to which 
participants from his or her class were aggressive to peers. Homeroom teachers rated the social behavior of every participant in their class on a shortened version of the Interpersonal Competence Scale (ICT-T; Cairns et al. 1995). This instrument contains three main subscales that assess aggression, popularity, and academic functioning. The reliability and predictive validity of these subscales has been demonstrated in previous studies (e.g., Cairns et al. 1995). In this study, we used a three-item subscale (i.e., starts fights, argues, gets in trouble) to assess externalizing/aggressive behavior $(\alpha=.89$ for this sample). Teachers rated each student on a 7-point scale with higher scores indicating that the descriptor was more characteristic of the student. To form the classroom index of aggression, students' scores on the three-item subscale were averaged within each classroom. Higher scores indicate greater aggression within the classroom. The mean for the 95 classrooms included in the analyses was 2.37, $\mathrm{SD}=.59$. Four teachers did not complete ratings of their students.

\section{Results}

Comparing Coolness Stability Groups on Spring Aggression

We conducted a 4 (coolness stability group) $\times 2$ (gender) $\times$ 5 (ethnicity) multivariate analyses of covariance (MANCOVA) comparing physical, verbal, and relational aggression in the spring. Gender, ethnicity, and spring social preference were included in the analyses as control variables.

The MANCOVA revealed multivariate main effects of coolness stability group (Wilks' $\Lambda=.97, F(9,3989)=$ 3.57, $p<.001, \eta^{2}=.01$ ), gender (Wilks' $\Lambda=.97, F(3$, $1639)=15.22, p<.001, \eta^{2}=.03$ ), and ethnicity (Wilks' $\left.\Lambda=.98, F(12,4336)=2.16, p<.05, \eta^{2}=.01\right)$ but no interactions. The between-subjects effects comparing boys and girls revealed that boys scored higher than girls on physical, $F(1,1641)=36.46, p<.001, \eta^{2}=.02$, verbal, $F(1,1641)=25.04, p<.001, \eta^{2}=.02$ and relational aggression $F(1,1641)=5.10, \quad p<.05, \quad \eta^{2}=.003$. The between-subjects effects comparing ethnic groups revealed ethnic group differences on physical aggression, $F(4,1641)=5.00, p<.01, \eta^{2}=.01$, verbal aggression, $F(4,1641)=5.69, p<.001, \eta^{2}=.01$, and relational aggression, $F(4,1641)=2.65, p<.05, \eta^{2}=.01$. Post hoc analyses for each type of aggression revealed that African American students scored higher than all other ethnic groups on physical and relational aggression and they scored higher than all other ethnic groups except for the "other" group on relational aggression. The only other ethnic group difference was that White students scored lower than Latinos on physical aggression.

The tests of between-subjects effects comparing coolness stability groups revealed group differences on all three types of aggression. Table 1 displays the means across the three groups for each type of aggression in the spring and the univariate $F$-test associated with that analysis. Post hoc analyses revealed that in the spring, students who maintained their cool status across the school year were perceived by their peers as being more physically, verbally, and relationally aggressive compared to those who were in the stable not cool group for all three types of aggression. For relational aggression, those students who were in the stable cool group scored higher than all three other stability groupings.

\section{Changes in Aggression from Fall to Spring}

In our second set of analyses, we used Hierarchical Linear Modeling (HLM; Raudenbush et al. 2000), to determine whether coolness stability group status predicted changes in aggression across the year and whether the association between coolness stability and changes in aggression differed as a function of the aggression behavioral norms present in the classrooms. Separately for each type of spring aggression outcome, a two-level model was run. At the student level we included a dummy-coded, uncentered, measure of coolness status stability group where we compared being in the stable cool group, became cool group and became not cool group to the group that was never

Table 1 Coolness stability group differences in average aggression in spring

\begin{tabular}{lllll}
\hline & $\begin{array}{l}\text { Stable cool } \\
M(\mathrm{SE})\end{array}$ & $\begin{array}{l}\text { Became cool } \\
M(\mathrm{SE})\end{array}$ & $\begin{array}{l}\text { Became not cool } \\
M(\mathrm{SE})\end{array}$ & \multicolumn{2}{l}{$\begin{array}{l}\text { Stable not cool } \\
M(\mathrm{SE})\end{array}$} \\
\hline Aggression & $n=85$ & $n=90$ & $n=92$ & $n=1415$ \\
Physical & $.33_{\mathrm{a}}(.12)$ & $.17_{\mathrm{ab}}(.16)$ & $.19_{\mathrm{ab}}(.12)$ & $-.04_{\mathrm{b}}(.03)$ \\
Verbal & $.33_{\mathrm{a}}(.12)$ & $.16_{\mathrm{ab}}(.16)$ & $.22_{\mathrm{a}}(.12)$ & $-.07_{\mathrm{b}}(.03)$ \\
Relational & $.58_{\mathrm{a}}(.13)$ & $.11_{\mathrm{b}}(.16)$ & $.10_{\mathrm{b}}(.13)$ & $-.08_{\mathrm{b}}(.03)$ \\
\hline
\end{tabular}

Row means with different subscripts are significantly different using the Least Significant Difference (LSD) test

$* p<.01 ; * * p<.001$ 
cool. In addition to fall measures of physical, verbal, and relational aggression, gender and ethnicity (dummy coded as White, Latino, Asian and Other compared to Black) were included as control variables. Each of these variables was group-mean centered. We chose Black students as the comparison group, because Black students were those who differed from the other ethnic groups in the MANCOVAs described earlier. We also included group-mean centered spring social preference as a control variable to examine the unique effects of the stability of coolness on changes in aggression. At the classroom level we tested the effects of the average level of teacher-rated aggression for the classroom on both the intercept of spring aggression and the slope between stable cool group status and spring aggression. This variable was grand-mean centered.

The results of the model predicting spring physical aggression revealed that our control variables were predictive of spring physical aggression. As displayed in Table 2, fall measures of each form of aggression were predictive of spring physical aggression as were gender and Latino and Asian ethnic group membership relative to African American group membership. Beyond these associations, as hypothesized, students who maintained their cool status across the school year demonstrated increases in their physical aggressive reputations from fall to spring relative to students who were in the never cool group. Students who attained cool status by spring also demonstrated increases in their physical aggressive reputations across the school year. See Table 2 for the coefficients and $\mathrm{t}$-tests of their significance for all variables included in this model.

The pattern of findings for verbal aggression was similar with fall measures of each form of aggression, gender, and Latino and Asian group membership predictive of spring verbal aggression. Spring social preference was also predictive of spring verbal aggression. As for physical aggression, students who maintained their cool status across the school year demonstrated increases in their verbal aggressive reputations from fall to spring relative to students who were in the never cool group. Moreover, the magnitude of this increase was greater when these students were in classrooms with higher levels of teacher-rated aggression. Students who attained cool status by spring also demonstrated increases in their verbal aggressive reputations across the school year.

For relational aggression, fall measures of each form of aggression were predictive of spring relational aggression, and White, Latino, and Asian students were viewed as less relationally aggressive relative to African American students. Above and beyond these effects, stable cool students

Table 2 Coolness stability group and classroom (fall average norms) predictors of students' spring aggression controlling for gender, ethnicity, fall aggression and spring social preference

\begin{tabular}{|c|c|c|c|c|c|c|c|c|c|}
\hline & \multicolumn{9}{|c|}{ Spring aggression } \\
\hline & \multicolumn{3}{|c|}{ Physical } & \multicolumn{3}{|c|}{ Verbal } & \multicolumn{3}{|c|}{ Relational } \\
\hline & Coefficient & Standard error & $t$-ratio & Coefficient & Standard error & $t$-ratio & Coefficient & Standard error & $t$-ratio \\
\hline Intercept & -.04 & .02 & -1.64 & $-.05^{*}$ & .02 & -2.04 & .04 & .02 & -1.74 \\
\hline Class Agg & -.05 & .04 & -1.20 & -.02 & .04 & -.42 & -.03 & .04 & -.64 \\
\hline Girl & $-.27 * * *$ & .04 & -5.94 & $-.24 * * *$ & .05 & -5.17 & -.07 & .05 & -1.52 \\
\hline White & -.16 & .09 & -1.71 & -.18 & .09 & -1.82 & $-.21 *$ & .10 & -2.10 \\
\hline Latino & $-.21 * * *$ & .06 & -3.36 & $-.19 * *$ & .06 & -2.94 & $-.22 * * *$ & .06 & -3.37 \\
\hline Asian & $-.20 *$ & .09 & -2.25 & $-.19 *$ & .09 & -2.06 & $-.23 *$ & .09 & -2.50 \\
\hline Other & -.15 & .09 & -1.65 & -.15 & .09 & -1.60 & -.17 & .09 & 1.81 \\
\hline Fall physical Agg & $.35 * * *$ & .03 & 10.62 & $.26 * * *$ & .03 & 7.61 & $.16 * * *$ & .03 & 4.76 \\
\hline Fall verbal Agg & $.15 * * *$ & .04 & 4.09 & $.18 * * *$ & .04 & 4.74 & $.17 * * *$ & .04 & 4.57 \\
\hline Fall relational Agg & $.12 * * *$ & .03 & 4.02 & $.15 * * *$ & .03 & 4.71 & $.28 * * *$ & .03 & 8.66 \\
\hline Stable cool & $.35 * * *$ & .10 & 3.68 & $.32 * *$ & .10 & 3.20 & $.31 * *$ & .10 & 3.07 \\
\hline Class Agg & .35 & .19 & 1.77 & $.48^{*}$ & .20 & 2.35 & .17 & .20 & .85 \\
\hline Became cool & $.28 * *$ & .10 & 3.00 & $.26 * *$ & .10 & 2.60 & $.21 *$ & .10 & 2.09 \\
\hline Class Agg & .06 & .15 & .41 & .05 & .16 & .29 & .00 & .16 & .01 \\
\hline Became not cool & .06 & .09 & .71 & .14 & .09 & 1.49 & .01 & .09 & -.52 \\
\hline Class Agg & -.08 & .15 & -.50 & -.26 & .16 & -1.67 & -.05 & .16 & -.16 \\
\hline Spring social Pref & .02 & .02 & .86 & $.05 *$ & .02 & 2.35 & -.03 & .02 & 1.26 \\
\hline
\end{tabular}

The reference group for the ethnicity dummy variables is African American; Agg = Aggression

$* p<.05 ; * * p<.01 ; * * * p<.001$ 
and those who became cool by spring displayed increases in relational aggression relative to the group who was never cool (See Table 2).

\section{Discussion}

During early adolescence when popularity is most strongly prioritized by youth (LaFontana and Cillessen 2010), students often feel the need to adopt the behaviors valued by their peer group to be at the top of their peer hierarchy. This study makes several new contributions to current understanding of the behaviors associated with adolescents' attempts to attain and maintain a high social status. First, maintaining a cool status across the first year of middle school was associated with having a more aggressive reputation than never attaining a cool status at any point in the school year. Second, coolness stability was also associated with changes in aggression across the school year. Compared to students who never attained a cool status, students who maintained or attained a cool status demonstrated gains in their aggressive reputations across all three types of aggression from fall to spring. Third, classroom aggression norms were found to moderate the association between coolness stability and changes in aggression over the year. For those who maintained their cool status, the increase in verbal aggression was larger for students in classrooms with higher levels of aggressive behavior. Together, the results from the present study speak to the fluidity of social status during the first year of middle school and suggest that a strategic use of aggression may promote the maintenance of high social status.

\section{Interplay Between Maintenance of Coolness and Aggression}

Previous studies have reported that descending the peer hierarchy is far more normative than ascending it (e.g., Lopes et al. 2002); however, these studies have not examined the factors that lead to changes in social status. Because we measured aggression in both fall and spring we were able to evaluate the interplay between status and aggression across development. This study captured students' aggressive reputations at the beginning of their sixth grade year, a period of time during which students are attempting to establish their social status in a new environment, and at the end of their sixth grade year when students are working to maintain their status or move up in the hierarchy. In our study, students who maintained their cool status across the school year were the students who had the highest aggressive reputations on all forms of aggression among their peers in spring compared to students who never attained a cool status. This held equally for both boys and girls and for students from all ethnic groups. To understand whether aggression is differentially associated with attainment versus the maintenance of coolness we can look to the patterns displayed by these two groups of students. The findings show that the spring aggression scores did not differ between the group of students who maintained their coolness and those who had attained a cool status by spring for physical and verbal aggression but they did differ for relational aggression. Students in the stable cool group had higher scores on relational aggression than did students in all other coolness stability groups. This finding provides support for the notion that the maintenance of high status may reflect a social competency that is also reflected by the use of relational aggression in particular (Andreou 2006).

The stability groupings also demonstrated differences in changes in aggression across the school year. Compared to students who never attained a cool status, students who maintained or attained a cool status demonstrated gains in their aggressive reputations across all three types of aggression from fall to spring. Although we focus on stability within middle school and the reference groups we utilize are a bit different, these findings are similar to Bowker et al.'s (2010) conclusion that increases in aggression were more strongly associated with gaining and maintaining status rather than a loss of status across the transition into middle school from elementary school. Further, in this study, for those who maintained their cool status, the increase in verbal aggression was larger for students in classrooms with higher levels of aggressive behavior. These results implicate the behavioral norms present within a social context as a contributor to the interplay between stable social status and changes in behaviors. It is possible that part of maintaining a high status may include an awareness of one's context and a negotiation of behaviors to match the context. Researchers are beginning to investigate the association between social intelligence and perceived popularity (e.g., Peeters et al. 2010), and the results of this study point toward identifying the social perception skills of popular adolescents as an important area for future research.

\section{Limitations}

In this study, we defined the peer group context as the classroom and we relied on teacher ratings of students to determine classroom norms. Although we believe that these methods capture the processes of interest, there are limitations to this approach. The classroom may not be the only relevant context for identifying influential social norms. Smaller contexts such as the norms of high status students have already been identified as influential in predicting behavior (Dijkstra et al. 2008) and larger contexts 
(e.g., the whole grade or school population) may also be influential. In multiethnic classrooms such as those studied here, it is also possible that relevant peer group contexts may break down along ethnic groupings. With our sample, we were able to explore whether there were ethnic group differences in the association that coolness stability has with aggression, and no differences were observed. However, in multiethnic contexts, several factors may influence how students' behaviors impact their popularity. These include which particular ethnic groups are in the setting, their relative representation, the behaviors that each ethnic group values, stereotypes that may be associated with particular ethnicities, and the extent to which the classroom context promotes or inhibits interactions between same and other ethnicity peers. For example, with a sample of rural White and Black adolescents, Meisinger et al. (2007) reported that some of the behaviors associated with perceived popularity differed depending on whether students resided in majority white or majority black classrooms. Like these researchers, we believe peer ethnic context variables to be more important than ethnicity per se in predicting whether the stability of coolness is differentially associated with aggression.

Another limitation related to our measurement of the peer group context is that the mean of teacher ratings of students' behaviors may not be the best way to capture the norms of classroom settings. Using an approach that captures counts of behaviors (e.g., teacher reports of office referrals for aggressive behavior over the course of a semester) or an observational approach that focuses more explicitly on the social climate of a classroom may better capture the richness of student norms in classroom contexts. Further, it is not clear how specific the match should be between the behavior used to measure classroom norms and the target behaviors of individual students. In this study, we used a general measure of aggressive and externalizing behavior to define classroom norms whereas we assessed specific forms of aggression at the student level. Another consideration is whether additional classroom characteristics beyond behavioral norms may be predictive of the association between the stability of status and aggression. For example, with elementary school students the association between perceived popularity and aggression has also been found to be strongest in classrooms that had more hierarchical peer structures (Ahn et al. 2010). The relative influence of different aspects of students' social contexts along with different measurements of classroom contexts should be examined in future research.

One other limitation of this study is faced by all researchers observing real-life phenomena as it unfolds. Although we measured both status and behaviors across the school year at two time points, we remain unable to make strong inferences about directionality in this study with respect to whether the stable high status students modify their behavior in response to behavioral norms, set the behavioral norms in a given setting, or are able to get away with certain behaviors that other students are sanctioned for. We also do not know how the coolness stabilityaggression associations will play out over longer periods of time. Eder (1985) suggests that there may be costs to being a member of a high status group because lower status peers may resent their higher status peers. Over time, this resentment may grow and change the opinions that the lower status adolescents hold of their peers. In the short term, stable cool students may be responding to norms or modifying norms, both of which would explain the match between their own behavior and that of their peer group. However, over longer periods of development, the same degree of similarity between student and peer group behavior may not facilitate status stability because of negative changes in how lower status peers come to view their high status peers. Only longer term studies can tease out which of these possibilities most accurately captures the social experiences of adolescents.

\section{Practical Implications of the Findings for School Settings}

The findings of this study are clear in showing that the stability of coolness is associated with more aggression and increased aggression over time relative to never attaining a cool status. The implications of these findings present several avenues of exploration for prevention efforts to reduce or eliminate school-based aggression. One avenue is to target cool youth to modify their aggressive behavior. Because this is the group who may be the most socially competent, they may be most effective in making changes to their own behaviors and subsequently shaping new positive norms within a peer group context. A second avenue would be to target classroom norms as a whole to modify individual student behavior. In this study, students with a stable cool status demonstrated correspondence between their classroom aggression norms and their own behavior. This suggests that prevention efforts that effectively reduce aggressive norms may change the behavioral currency adopted by high status youth to maintain their high status. A third avenue would be to modify the values held by the classroom (i.e., encourage youth to reject aggressive behavior) so that even if actual aggressive behavior is not reduced, it is no longer associated with a cool status. No matter the approach taken, an important first step is that taken in this study which is the identification of the behaviors that promote the maintenance of a high status. 
Acknowledgment Data for the study were collected with the support of grants from the National Science Foundation and the William T. Grant Foundation (Sandra Graham and Jaana Juvonen, PIs).

Open Access This article is distributed under the terms of the Creative Commons Attribution Noncommercial License which permits any noncommercial use, distribution, and reproduction in any medium, provided the original author(s) and source are credited.

\section{References}

Adler, P. A., \& Adler, P. (1995). Dynamics of inclusion and exclusion in preadolesent cliques. Social Psychology Quarterly, 58, $145-162$.

Adler, P. A., Kless, S. J., \& Adler, P. (1992). Socialization to gender roles: Popularity among elementary school boys and girls. Sociology of Education, 65, 169-187.

Ahn, H., Garandeau, C., \& Rodkin, P. (2010). Effects of classroom embeddedness and density on the social status of aggressive and victimized children. The Journal of Early Adolescence, 30, 76-101. doi:10.1177/0272431609350922.

Andreou, E. (2006). Social preference, perceived popularity and social intelligence: Relations to overt and relational aggression. School Psychology International, 27, 339-351. doi:10.1177/014 3034306067286

Bowker, J., Rubin, K., Buskirk-Cohen, A., Rose-Krasnor, L., \& Booth-LaForce, C. (2010). Behavioral changes predicting temporal changes in perceived popular status. Journal of Applied Developmental Psychology, 31, 126-133. doi:10.1016/j.appdev. 2009.10.002.

Cairns, R., \& Cairns, B. (1991). Social cognition and social networks: A developmental perspective. In D. Pepler \& K. Rubin (Eds.), The development and treatment of childhood aggression (pp. 249-278). Hillsdale, NJ: Lawrence Erlbaum.

Cairns, R. B., Leung, M. C., Gest, S. D., \& Cairns, B. D. (1995). A brief method for assessing social development: Structure, reliability, stability, and developmental validity of the interpersonal competence scale. Behavioral Research and Therapy, 33, $725-736$.

Cillessen, A. (2009). Sociometric methods. Handbook of peer interactions, relationships, and groups (pp. 82-99). New York, NY, US: Guilford Press.

Cillessen, A. H. N., \& Bellmore, A. D. (in press). Social skills and social competence in interactions with peers. In P. K. Smith \& C. H. Hart (Eds.). The Wiley-Blackwell handbook of childhood social development (2nd edn). Hoboken, NJ: Blackwell Publishing.

Cillessen, A. H. N., Bukowski, W. M., \& Haselager, G. J. T. (2000). Stability of sociometric categories. In Recent advances in the measurement of acceptance and rejection in the peer system (pp. 75-93). San Francisco, CA, US: Jossey-Bass.

Cillessen, A. H. N., \& Mayeux, L. (2004). From censure to reinforcement: Developmental changes in the association between aggression and social status. Child Development, 75, 147-163.

Cillessen, A. H., \& Rose, A. J. (2005). Understanding popularity in the peer system. Current Directions in Psychological Science, 14, 102-105.

Closson, L. M. (2008). Status and gender differences in early adolescents' descriptions of popularity. Social Development, 18 , 412-426.

Coie, J. D., Dodge, K. A., \& Coppotelli, H. (1982). Dimensions and types of social status: A cross-age perspective. Developmental Psychology, 18, 557-570.
Corsaro, W. A., \& Eder, D. (1990). Children's peer cultures. Annual Review of Sociology, 16, 197-220.

Dijkstra, J. K., Lindenberg, S., \& Veenstra, R. (2008). Beyond the class norm: Bullying behavior of popular adolescents and its relation to peer acceptance and rejection. Journal of Abnormal Child Psychology, 36, 1289-1299.

Eccles, J., \& Midgley, C. (1989). Stage/environment fit: Developmentally appropriate classrooms for early adolescents. In R. Ames \& C. Ames (Eds.), Research on motivation in education (Vol. 3, pp. 139-181). New York, NY: Academic Press.

Eder, D. (1985). The cycle of popularity: Interpersonal relations among female adolescents. Sociology of Education, 58, 154-165.

Hawley, P. H. (2003). Prosocial and coercive configurations of resource control in early adolescence: A case for the welladapted Machiavellian. Merrill-Palmer Quarterly, 49, 279-309.

Hoff, K. E., Reese-Weber, M., Schneider, W. J., \& Stagg, J. W. (2009). The association between high status positions and aggression in early adolescence. Journal of School Psychology, 47, 395-426.

Juvonen, J., \& Ho, A. Y. (2008). The social motives underlying antisocial behavior across middle school grades. Journal of Youth and Adolescence, 37, 747-756.

LaFontana, K. M., \& Cillessen, A. H. (2002). Children's perceptions of popular and unpopular peers: A multimethod assessment. Developmental Psychology, 38, 635-647.

LaFontana, K., \& Cillessen, A. (2010). Developmental changes in the priority of perceived status in childhood and adolescence. Social Development, 19, 130-147. doi:10.1111/j.1467-9507.2008.00522.x.

Lopes, J., Cruz, C., \& Rutherford, R. B. (2002). The relationship of peer perceptions to student achievement and teacher ratings of 5th and 6th grade students. Education \& Treatment of Children, $25,476-495$.

Magnusson, D., \& Cairns, R. B. (1996). Developmental science: Toward a unified framework. In R. B. Cairns \& G. H. Elder Jr (Eds.), Developmental science. Cambridge studies in social and emotional development (pp. 7-30). New York, NY: Cambridge University Press.

Meisinger, E. B., Blake, J. J., Lease, A. M., Palardy, G. J., \& Olejnik, S. F. (2007). Variant and invariant predictors of perceived popularity across majority-Black and majority-White classrooms. Journal of School Psychology, 45, 21-44.

Merten, D. E. (1997). The meaning of meanness: Popularity, competition, and conflict among junior high school girls. Sociology of Education, 70, 175-191.

Nylund, K., Bellmore, A., Nishina, A., \& Graham, A. (2007). Subtypes, severity, and structural stability of peer victimization: What does latent class analysis say? Child Development, 78, $1706-1722$.

Parkhurst, J. T., \& Hopmeyer, A. (1998). Sociometric popularity and peer-perceived popularity: Two distinct dimensions of peer status. The Journal of Early Adolescence, 18, 125-144.

Peeters, M., Cillessen, A., \& Scholte, R. (2010). Clueless or powerful? Identifying subtypes of bullies in adolescence. Journal of Youth and Adolescence, 39, 1041-1052. doi:10.1007/ s10964-009-9478-9.

Pellegrini, A. D., \& Bartini, M. (2000). A longitudinal study of bullying, victimization, and peer affiliation during the transition from primary school to middle school. American Educational Research Journal, 37, 699-725.

Pellegrini, A. D., \& Long, J. D. (2002). A longitudinal study of bullying, dominance, and victimization during the transition from primary school through secondary school. British Journal of Developmental Psychology, 20, 259-280.

Raudenbush, S. W., Bryk, A. S., \& Congdon, R. (2000). HLM for windows. Version 6. Lincolnwood, IL: Scientific Software International, Inc. 
Rodkin, P., Farmer, T., Pearl, R., \& Van Acker, R. (2006). They're cool: Social status and peer group supports for aggressive boys and girls. Social Development, 15, 175-204. doi:10.1111/j.14679507.2006.00336.x.

Rose, A. J., Swenson, L. P., \& Waller, E. M. (2004). Overt and relational aggression and perceived popularity: Developmental differences in concurrent and prospective relations. Developmental Psychology, 40, 378-387.

Rubin, K. H., Bukowski, W. M., \& Parker, J. G. (2006). Peer interactions, relationships, and groups. In Handbook of child psychology (6th ed., Vol. 3, pp 571-645). Social, emotional, and personality development.

Sandstrom, M. J., \& Cillessen, A. H. N. (2006). Likable versus popular: Distinct implications for adolescent adjustment. International Journal of Behavioral Development, 30, 305-314.

Schäfer, M., Korn, S., Brodbeck, F. C., Wolke, D., \& Schulz, H. (2005). Bullying roles in changing contexts: The stability of victim and bully roles from primary to secondary school. International Journal of Behavioral Development, 29, 323-335.

Stormshak, E. A., Bierman, K. L., Brushi, C., Dodge, K. A., Coie, J. D., \& The Conduct Problems Prevention Research Group. (1999). The relation between behavior problems and peer preference in different classroom contexts. Child Development, $70,169-182$

Wright, J. C., Giammarino, M., \& Parad, H. W. (1986). Social status in small groups: Individual-group similarity and the social "misfit". Journal of Personality and Social Psychology, 50, 523-536.

\section{Author Biographies}

Amy Bellmore is an Assistant Professor at the University of Wisconsin-Madison in the Department of Educational Psychology. She received her Ph.D. in Developmental Psychology from the University of Connecticut. Her primary research interest is how school-based peer relationships influence development during adolescence, including how being a victim or perpetrator of peer-directed aggression impacts academic and psychosocial adjustment. She is particularly interested in the significance of ethnicity and ethnic contexts for students' intra- and inter-group relations.

Vanessa M. Villarreal is the project manager of the Middle School Diversity Project at the University of California, Los Angeles. She received her B.A. from the University of California, Los Angeles. Her major research interests include adolescent social development, prosocial behavior, friendships, community service learning, and school diversity.

Alice Y. Ho is the Director of Mentoring and Research Programs with the Academic Advancement Program at the University of California, Los Angeles. She received her Ph.D. in Education from the University of California, Los Angeles. Her primary research interests include college student development, ethnic identity development and school diversity, and academic achievement. 